\title{
Reward value of saline and water for the rat
}

Elizabeth M. Stearns I BROWN UNIVERSITY

\begin{abstract}
Abstraet
Rats given a choice between $.8 \% \mathrm{NaCl}$ and distilled water in a $\mathrm{T}$-maze increased their choices of $\mathrm{NaCl}$ over days. The critical difference between this study and others in which rats preferred water to saline in the $\mathrm{T}$-maze seems to be the amount of time during which $\mathrm{S}$ is allowed to drink.
\end{abstract}

\section{Problem}

There has been some controversy in recent years over the so-called preference of the rat for weak concentrations of $\mathrm{NaC1}$. Several experimenters have found that rats prefer $.8 \% \mathrm{NaC} 1$ to water, and that this preference is independent of whether the solutions are presented singly or together and whether the rat is thirstv or not (Stellar \& McCleary, 1952; Weiner \& Stellar, 1952; Stellar et al, 1954). Deutsch \& Jones (1960) and Chiang \& Wilson (1963) showed, however, that when thirsty rats are rewarded in one arm of a $\mathrm{T}$-maze with $.8 \% \mathrm{NaC1}$ and in the other arm with water, they come to choose the water arm more frequently.

To reconcile these seemingly contradictory results, Deutsch \& Jones proposed the diluted-water hypothesis. This hypothesis is based on the data of Zotterman (1956) showing that the rat has no taste fiber which responds specifically to water, but that the discharge rate of salt fibers is reduced by water. Deutsch \& Jones suggested that hypotonic saline solutions produce a smaller decrement in neural firing than does water, and therefore more hypotonic saline than water must be drunk to produce an equivalent water signal.

There are several indications that this interpretation is incorrect. In the first place, Zotterman rinsed the tongue with Ringer's solution, which is roughly . $8 \%$ $\mathrm{NaC1}$; the salivary sodium level of the rat is probably much lower than this (Schneyer \& Schneyer, 1959), and it has been shown that whether a decrement of an increment results from the application of a salt solution to the tongue depends on the concentration to which the tongue is adapted (Pfaffmann \& Powers, 1963). In the second place, other behavioral experiments have given results which are contradictory to the predictions which would be made from the hypothesis. Chiang \& Wilson (1963) found that during a two-bottle test, rats approach the saline bottle more often than the water bottle, rather than merely taking longer drinks from the saline bottle. Falk \& Titlebaum (1963) showed that thirsty rats will abstain from drinking during a period of access to water which is regularly followed by access to $\mathrm{NaC1}$, but will drink $\mathrm{NaCl}$ when water is regularly available thereafter. Fisher (1965) found that rats licking at a tube of water will switch to a tube of $\mathrm{NaC} 1$ when $\mathrm{NaC} 1$ is presented, but will not switch from $\mathrm{NaC} 1$ to water. It appears from these experiments that $\mathrm{NaC1}$ is in fact more reinforcing than water.

The reason for the discrepant results is suggested by an experiment by Young \& Falk (1956), who found that when rats were given access to water and $\mathrm{NaC1}$ for brief periods of time (1-2 sec.), the preferences of thirsty rats for $\mathrm{NaCl}$ were weaker than those of nonthirsty rats. Furthermore, only 7 of their 12 animals gave good evidence of a preference for concentrations around $.8 \%$, even when nondeprived. It therefore appears that thirst and short drinking times, conditions which were present in the Deutsch \& Jones experiment, are conditions which are unfavorable to the demonstration of a salt preference. The present experiment was designed to test the hypothesis that a salt preference could be demonstrated in the $\mathrm{T}$-maze merely by increasing the duration of exposure to the solutions.

\section{Method}

The Ss were 10 female albino rats of the Charles River COBS strain, weighing an average of $300 \mathrm{gm}$ at the start of the experiment. They were maintained on Purina Lab Chow checkers and tap water a d lib itu m for two weeks after arriving at the laboratory, and thereafter on $20 \mathrm{gm}$ ground Purina Chow mixed with $15 \mathrm{ml}$ distilled water, fed about $1 / 2 \mathrm{hr}$. after completion of the daily session, plus the fluid received during the experiment.

The apparatus was a wooden $\mathrm{T}$-maze, painted flat gray and entirely covered with hardware cloth. The stem was $3 \mathrm{ft}$ long and the arms including the goal boxes $2 \mathrm{ft}$ long. Hinged floors in the start box, choice point, and goal box entrances permitted automatic timing. There was a hole in the back wall of each goal box for the insertion of a drinking tube, and a clip on the outside of the wall held a graduated cylinder.

The day after the start of water deprivation (Day 1), single bottle preference tests were begun. At the same time each day, a graduated cylinder containing either $.8 \% \mathrm{NaC1}$ or distilled water was placed on each S's home cage, and intake for the next $15 \mathrm{~min}$. recorded to the nearest $\mathrm{ml}$. Half the animals received water and half received $\mathrm{NaC1}$ on Day 1 , and on Days 2-20, the solution which each animal received was determined by an irregular order. On Days 21-25, each $\mathrm{S}$ was given one unrewarded exploration trial in the T-maze daily. The $\mathrm{S}$ was placed in the start box and removed about $30 \mathrm{sec}$. after entering one of the goal boxes. Choices and running times were recorded. Single bottle preference tests were given $1 / 2 \mathrm{hr}$. after the exploration trial. On the 26th day, rewarded trials in the T-maze began, and preference tests were discontinued. Each $\mathrm{S}$ 


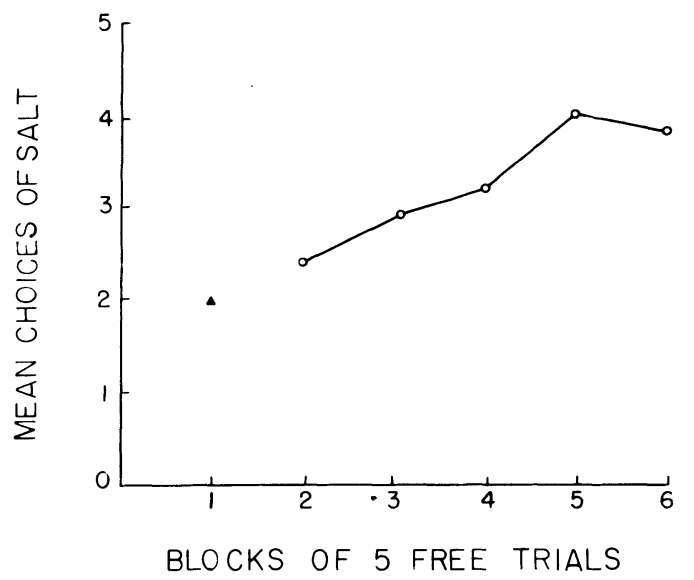

Fig. 1. Choices of sodium chloride as a function of trials. The first block of trials was unrewarded.

was given one trial per day in the $\mathrm{T}$-maze, NaC1 being located in the goal box chosen less often during the exploration trials for each $\mathrm{S}$. The $\mathrm{S}$ was left in the goal box for $15 \mathrm{~min}$. after the first lick. On Day 27 each $\mathrm{S}$ was forced to the solution not chosen on the previous day, and for the following 47 days, free and forced choices were alternated, fluid consumption, running times, and choices being recorded. All choice trials were noncorrection, and $S$ was left in the goal box for $15 \mathrm{~min}$. on every trial.

\section{Results and Discussion}

During the first 10 days of the home cage preference tests, 8 of the 10 Ss showed $\mathrm{NaCl}$ preferences significant at the .05 level or better (Mann-Whitney $U$ test, two-tailed), and during the second 10 days, $\mathrm{NaC} 1$ preferences for all Ss were significant at or beyond the .05 level.

Although all of the Ss showed $\mathrm{NaCl}$ preferences in the home cages, only 7 of the 10 learned to run to $\mathrm{NaC1}$; that is, ran at least 7 times in the last 10 free choice trials to $\mathrm{NaCl}$. Two other animals seemed to be choosing the two sides with about the same frequency as before training, and one $\mathrm{S}$ was running consistently to water.

Group data for the free choice trials are plotted in Fig. 1. An increasing number of runs to the $\mathrm{NaC1}$ throughout the experiment is apparent. For each $\mathrm{S}$, the number of runs to the $\mathrm{NaC} 1$ side during the five unrewarded exploration trials (Days 21-25) was com- pared to the number of runs to the $\mathrm{NaCl}$ side during successive five-day blocks of free choice days. This measure, which traces the change in behavior associated with introduction of $\mathrm{NaCl}$ and water into the goal boxes, reveals a systematic increase in turns to the side with the salt solution. For the last two blocks of free choice trials, this increase in choices of the NaC1. side was statistically significant (last block: $t=3.45 ; \mathrm{p}<.01$; next to last block: $t=4.16 ; p<.01)$. These data show clearly the inadequacy of Deutsch \& Jones' hypothesis. Together with previous experiments, they also suggest that length of drinking time, as well as the quality of taste stimulation and thirst, is important in determining preference. Pfaffmann's (1963) suggestion that Deutsch \& Jones' animals learned to run to water because they never drank enough fluid to satisfy their thirst (and hence, for the taste difference to be important) appears to be supported.

\section{References}

CHIANG, H. M., \& WILSON, W. A., JR. Some tests of the diluted water hypothesis of saline consumption in rats. J. comp. physiol. Psychol., 1963, 56, 660-665.

DEUTSCH, J. A., \& JONES, A. D. Diluted water: An explanation of the rat's preference for saline. J. comp. physiol. Psychol., 1960, $53,122-127$.

FALK, J. L., \& TITLEBAUM, L. F. Saline solution preference in the rat: Further demonstrations. J. comp. physiol. Psychol., 1963, $56,337-342$.

FISHER, G. L. Saline preference in rats determined by contingent licking. Manuscript in preparation.

PFAFFMANN, C. Taste stimulation and preference behavior. In In Y. Zotterman (Ed.), Olfaction and taste. Oxford: Pergamon Press. 1963.

PFAFFMANN, C., \& POWERS, J.B. Partial adaptation of taste. Psychon. Sci., 1964, 1, 41-42.

SCHNEYER, C. A., \& SCHNEYER, L. H. Electrolyte levels of rat salivary secretion. Proc. Soc: Exp. Biol. Med., 1959, 101, 568-569.

STELLAR, E., HYMAN, R., \& SAMET, S. Gastric factors controlling water and salt-solution drinking. J. comp. physiol. Psychol., $1954,47,220-226$.

STELLAR, E。, \& McCLEARY, R. A. Food preference as a function of the method of measurement. Amer. Psychologist. 1952, 7, 256. (Abstract)

WEINER, I. H., \& STELLAR, E. Salt preference of the rat determined by a single-stimulus method. J. comp. physiol. Psychol., 1951, 44, $394-401$.

YOUNG, P. T., \& FALK, J. L. The relative acceptability of sodium chloride as a function of concentration and water need. J. comp. physiol. Psychol, 1956, 49, 569-575.

ZOTTERMAN, Y. Species differences in the water taste. Acta Physiol. Scand., 1956, 37, 60-70.

Note

1. This research was carred out while the author was a PHS predoctoral Fellow. The author is grateful to Dr. Mark A. Berkley for many helpful suggestions. 